\title{
Planning for learning and learning about planning in social work fieldwork
}

\section{David Hodgson $^{1}$ and Heather Walford ${ }^{2}$}

Summary: Fieldwork education is a crucial component of social work education. Many social work students regard their placement experiences as the most profound learning experiences of their studies. The students undertake their field placements in a diverse range of organisational contexts, and in so doing perform a myriad of tasks, adopt a variety of roles, implement a range of practices, and engage with numerous people. Needless to say, social work students have a rich set of learning opportunities within such diversity. An important part of the fieldwork process is the development of learning plans; these plans guide and direct the students' roles, tasks and learning, and are often an important framework by which assessment of competency and learning takes place. However, learning plans presuppose a logical and conceptual clarity, which needs to be learned if they are to be functional and effective documents. This then poses many challenges in relation to how students might develop a learning plan for fieldwork. This paper explores some of the problems, and offers practical guidance, for students and fieldwork educators to develop rational learning plans in diverse and complex contexts.

Keywords: Social work, Fieldwork, planning, learning

1. Associate Lecturer in Social Work at Edith Cowan University in Bunbury, Western Australia.

2. Participation Coordinator for the Department of Education and Training in Western Australia (formerly, Social Work Fieldwork Coordinator, Edith Cowan University).

Address for Correspondence: Edith Cowan University, Robertson Drive, Bunbury, WA6230,Australia.d.hodgson@ecu.edu.au.heather.walford@det.wa.edu.

50 Journal of Practice Teaching \& Learning 7(1) 2006-07, pp.50-66. @ 2007 Whiting \& Birch Ltd 
Planning for learning and learning about planning in social work fieldwork

\section{Introduction}

Fieldwork is an important part of the education of social work students. In Australia, the Australian Association of Social Workers (AASW) stipulates that social work students should spend at least 980 hours in fieldwork 'in at least two practice settings, and in at least two fields of practice and be able to practise using a diverse range of social work interventions' (AASW, 2000, p.8). The AASW (2000) also states that a 'learning plan must be developed for each placement, indicating how the student will meet the required goals and objectives' (p.9) and that 'methods of assessing field performance should respect and promote academic rigour' (p. 9).

Whereas this paper has a focus on learning (more specifically, learning plans) it should be clear that it does not discuss theories, methods or styles of learning. These are, of course, important areas of consideration when planning and educating for fieldwork. However, such a discussion is beyond the scope of this paper, which is concerned with some of the practical dilemmas that students and educators may encounter when constructing learning plans. Developing adequate learning plans is not straightforward as there are conceptual and logical matters that must be addressed if such plans are to be useful, rigorous documents.

We begin this paper by explaining the basic components of learning plans. Following this, and by way of example, we outline the components of a rational planning framework that commonly underpins a range of learning plan designs. This will be the basis of explaining how some conceptual and logical problems may arise in developing learning plans, and what can be done about them. Our exposition of the argument and examples below are based on our years of liaison work with students on placement, and our attempts to work with the frustrations and difficulties associated with poorly developed learning plans. Such problems inevitably lead to learning plans that are often seen to have little relevance or utility and, as such, are undervalued as important learning tools.

51 Journal of Practice Teaching \& Learning 7(1) 2006-07, pp.50-66. ( 2007 Whiting \& Birch Ltd 


\section{Learning plans}

Establishing a learning plan is an integral part of social work fieldwork placements. In effect, a learning plan is the tool that is established by students and fieldwork educators, in context, to assist them to know what they will be learning and doing for the period of time they are in an agency (O'Connor, Wilson \& Setterlund, 2003). A learning plan needs to be formally reviewed by the university and informally via supervision. It is therefore a tool that can be used by educators for assessing a student's progress and performance, insofar as the student's learning goals may need to be revised during important assessment events, such as the mid-placement assessment (Cleak \& Wilson, 2004). Learning plans, therefore, attempt twin tasks: they plan for the future and they articulate what has been achieved at critical junctures.

In reviewing the literature on learning plans, it is noticed that there are some similarities in what is commonly understood to encompass the basic components of the learning plan in social work field work. A learning plan typically falls under the rubric of 'a written document in which your learning goals are specifically identified as well as the strategies or activities for accomplishing each goal' (Kiser, 2000, p. 26). In general, learning plans structure and predict relationships between goals, strategies, and methods of measurement (Rogers \& Langevin, 2000; Kiser, 2000; Shardlow and Doel, cited in Cleak \& Wilson, 2004). Table 1 (overleaf) is an example of how these relationships may be structured in a documented format. It is an adaptation of the core elements of a learning plan framework from Cleak and Wilson (2004) and a learning plan template we have used in our practice with social work students on placement from 2001-2006 (ECU, 2006).

A learning plan is a contextual and specific tool and can be used in tandem with the more fixed and generic nature of learning contracts. Learning contracts stipulate generic goals and objectives and standard conditions and expectations of fieldwork. Whereas, learning plans are more incrementally prepared around a particular student and his or her placement context. For example, Cleak and Wilson (2004, p.44-45) state that broad expectations are usually derived from the university curriculum and/or agency context and as such are not always negotiable. An example of this might be 'to develop an understanding of professional values and ethics' (Cleak \& Wilson, 2004, p.46). With regards to Table 1, the generic learning expectation would be situated in the row

52 Journal of Practice Teaching \& Learning 7(1) 2006-07, pp.50-66. ( 2007 Whiting \& Birch Ltd 
Planning for learning and learning about planning in social work fieldwork

Table 1

Basic components of a learning plan

\begin{tabular}{ll} 
Broad objective concept & $\begin{array}{l}\text { What is the broad focus of my practice(s)/ } \\
\text { learning }\end{array}$ \\
\hline Practice activity & What will I do? \\
\hline Evidence of practice activity & How will I know I have done it? \\
\hline Learning objective or goal & What will/did I learn? \\
\hline Evidence of learning & $\begin{array}{l}\text { How will I demonstrate/articulate my } \\
\text { learning? }\end{array}$ \\
\hline Timeline & When will I start/complete my practice \\
& objectives?
\end{tabular}

marked 'broad objective concept'. Thus, the particular details in the learning plan that need to be developed by the student and supervisor would set in motion the realistic strategies and goals that operationalise such an objective.

A learning plan needs to encompass planning for more abstract dimensions of knowledge, values, and skills (Garthwait, 2005). In a fieldwork placement knowledge learnt in the classroom can be tested, values can be challenged, and skills can be practised. Although these three areas are interwoven, in a learning plan they can be conceptualised in a way to ensure that they are specifically addressed. These are, however, more difficult to conceptualise and articulate as they tend to exist more in the abstract, than say, the observable dimensions of simply carrying out a specific task. Regardless, the ethics and values of practice can be incorporated into all aspects of a learning plan through the strategies of dialogue and reflection. Briggs and Kane (2000) argue that integrating ethics and values into practice involves 'honest, open debate - preferably involving all the parties in the fieldwork enterprise' (p.144). What this means is that a learning plan should not simply focus on the technical aspects of carrying out specific tasks, but the processes involved in reflective learning, such as in supervision.

For example, Rogers and Langevin (2000) frame learning experiences in relation to being, knowing, doing and thinking. The learning dimensions of 'being', such as empathy; 'knowing', such as theories and concepts; and 'thinking', such as cognition and reflection are harder to

53 Journal of Practice Teaching \& Learning 7(1) 2006-07, pp.50-66. () 2007 Whiting \& Birch Ltd 
conceptualise, plan and evaluate than 'doing' - the latter involving skills, behaviours and tasks (Rogers \& Langevin, 2000). As such, whereas learning plans negotiated in context may loosely encapsulate all of the dimensions of learning anticipated by Rogers and Langevin (2000), some kind of conceptual framework or guideline is necessary to organise learning experiences in a coherent manner. This becomes all the more important given that practice occurs within a complex and uncertain environment, which can obfuscate the ability to clearly describe learning (Lishman, 2002).

Thus, the relatively straightforward needs for a coherent and workable learning plan belie the complexity involved in actually developing one (Garthwait, 2005, p. 21). The major challenge in establishing a learning plan is that multiple factors, many of them conflicting or unapparent, need to be negotiated and incorporated into the plan (Rogers \& Langevin, 2000). First, the expectations of learning are dependent on a mixture of the university's requirements, the learning opportunities available in the agency, the starting point and abilities of the student, and the supervisor's abilities and relationships within the agency (Cleak \& Wilson, 2004). These need to be carefully and thoughtfully considered in developing plans.

Learning plans, in this sense, are helpful in identifying gaps in learning opportunities available to the student; any limitations in learning possibilities can be identified and addressed. For example, the student can potentially use a learning plan to arrange alternative or additional learning opportunities and experiences, and is thus empowered to initiate a renegotiation of the functions of their placement. Secondly, the path of action and the learning goals attained need to be clearly articulated should they be able to operate as a framework for assessment. The ideal outcome is that a learning plan is organised in such a manner as to presuppose some element of causality, in which it is assumed that practical activities operate as 'sufficient conditions' for learning (Munson, Conway \& Black, 2004, p. 100). In order to meet this ideal, the problems and benefits of using a rational plan need careful critical analysis. 


\section{Issues associated with learning plans: Conceptual and logical problems}

As indicated, it is necessary to think carefully about the type of model that implicitly underpins the learning template exemplified above. This template is characteristic of a rational planning model that is quite commonly used as a means of designing a strategy for planning goals and outcomes. For this model to work well there should be logical connections between the outcome, the strategy, and the means by which the achievement is measured. This approach is extremely useful for bounded and discontinuous projects such as fieldwork; however, there are a couple of important points to be made about this model that needs to be considered in order to ensure that this approach is most effective.

First, the moment we enter into discussions about plans that involve considered choice, we are talking about a form of rationality (Ham \& Hill, 1993; Kahn, 1969). According to Kahn (1969) rationality in planning may sit somewhere on a continuum between being 'all encompassing', or 'modestly incomplete'. As Kahn states:

Rational planning in this sense may be comprehensive, indicating the principle acts by which major ends are to be attained, or it may be partial, focussing only on some important and subordinate ends. (p.333).

In the case of field work learning plans, a comprehensive plan is one in which there are significantly stated practices to which certain learning outcomes are predicted, or there may be bounded and particular practices aimed at very discreet learning outcomes. Regardless, as Kahn (1969) indicates, rational planning, while a valuable instrument, should not be seen as unproblematic:

In a sense, rational planning is like formal organization. Just as the organizational theorist or administrator may, indeed must, relate systematically to informal organization, so must the planner think systematically about and provide for the irrational, the political, the unmanageable. (p. 340).

In this sense, learning plans that presume a degree of rationality must be examined in the context of the limitations of such plans.

55 Journal of Practice Teaching \& Learning 7(1) 2006-07, pp.50-66. ( 2007 Whiting \& Birch Ltd 
Most basically, rationality in the context of learning plans initially refers to a form of a priori knowledge, or reasoned knowing, in which the student is required to establish a conceptual and logical framework that integrates her doing and learning, and guides her practice into the future. Hence the need for a priori knowledge early in their placement; that is, a form of knowledge that is initially 'independent of observational evidence' and is 'arrived at by reason and reasoning' (Wall, 2001, p. 147). Students' ability to work in a rational framework and their learning style can sometimes be at odds, and this is because 'whatever their reason for doing fieldwork, each student will approach the learning tasks in a different manner' (Cooper \& Briggs, 2000, p. 5).

For example, in our experience, whereas some students embrace the learning plan, others may avoid it and claim it is not a useful tool for them, preferring instead to discover their placement experiences and learning, rather than plan in advance. Equally, some students may feel overwhelmed about the broadness and diversity of social work and be pulled in many different directions, directions that are hard to reconcile in an a priori planning framework. In addition, a supervisors' understanding of this kind of tool to facilitate learning and their commitment to it may also vary. Some supervisors may not be comfortable with a rational framework and, moreover, some policy, practice and agency contexts can be read as being so chaotic, uncertain and politicised, that the perceived unpredictability associated with an ever shifting context makes plans appear more or less redundant (Kahn, 1969). This begs the question: if learning plans are seen as important and are expected, how might students, with support from supervisors and educators, develop clear, coherent and useful learning plans?

Part of the answer to this question depends on the kinds of instruction students receive through their academic studies prior to entering fieldwork. In our experience, students often treat the learning plan as if it is a method of fixing reality and make the mistake alluded to by Kahn (1969) in which a necessary degree of incrementalism arising out the informal and the political context of practice is forsaken. A learning plan should be seen as more or less fluid and subject to some incremental revision, rather than overly rigid and concrete. It is, after all, a guide to planning and measuring outcomes (Garthwait, 2005). It should be treated as reasonably fluid because any learning goals and strategies developed early in the placement that are pursued in a rigidly dogmatic fashion risk overly narrowing and limiting the kinds 
of learning opportunities available. Such an approach may undervalue 'incidental, accidental or serendipitous learning' (Rogers \& Langevin, 2000, p.216) and as such it is entirely necessary to renegotiate the plan. Organisations are diverse (Jones \& May, 1992) and social work practice is fraught with complexity and uncertainty (Lishman, 2002); preparation of an adequate learning plan should be sensitive to this. Focussing too rigidly on learning goals conceived early in the placement runs the risk of failing to develop learning that arises through engagement with the 'fluid, emergent, socially negotiated' (Comerford, 2005, p. 114) context of practice. Good learning opportunities may occur that are not noticed or assessed precisely because the learning plan is not orientated towards them, or fails to adapt incrementally.

In summary, a learning plan should aim to capture as many aspects of the learning experiences and outcomes as possible, as well as provide direction for that learning. There needs to be a careful balancing of the ebbs and flows of the placement experience with the demands for some certainty and predictability that such plans dictate. Secondly, and in many ways this is related to the first point, it is always possible that there will be a gap between the reality of the student's placement experiences and the rhetorical conceptualisation of the learning plan. This kind of information is helpful for students if they are to take a flexible and reflexive approach to developing rational plans.

\section{Steps in developing a logical and conceptually coherent learning plan}

We take the position that learning plans are necessary and potentially useful documents, but at the same time, require some thought and analysis during their development. The following illustrates some common errors in developing learning plans, and what might be done about them.

When students commence fieldwork, some of the first questions they ask (and will be asked of them) are: What will I actually do? What opportunities are available and potentially available? What is the daily work of the agency and what can I get involved in? The answers to these questions constitute the activities that comprise the work of the placement experience; these may take some time to work out as students orientate themselves to their placement context and negotiate initial agreements with supervisors and 
other stakeholders. Learning plans develop through a negotiation between all parties involved in the fieldwork placement (Rogers \& Langevin, 2000; Hughes \& Heycox, 2000). The educational institution will usually provide some guidelines as to the desired areas of learning in the placement and this may differ depending on whether it is a first or second placement. Furthermore, the student will be seeking learning in particular areas and the supervisor will be directing the learning according to the roles and functions undertaken within the agency setting (Hughes \& Heycox, 2000, p.85).

To manage some of these issues, Rogers and Langvin (2000) argue for a particular approach to negotiation that is sensitive to difference and power. They state that although there are usually non-negotiable expectations on what are required learning, field educators and supervisors can respectfully incorporate these with the students needs for flexibility. This involves avoiding authoritarian and arrogant dictates on what the learning plan ought to resemble, and instead pay particular attention to dialogue and participation in ways that incorporate the interests of the university, the field agency and the student. The ideal scenario is a mutually satisfactory outcome that will 'stimulate, foster and sustain the goal of learning' (Rogers \& Langevin, 2000, p.221).

At its base, the kind of planning encapsulated in a learning plan is primarily concerned with the negotiation of tasks or activities; for example, establishing a group for new parents, coordinating casework, or conducting a small research project. Tasks and activities are typically easier to identify and incorporate into a plan because they are more concrete and observable than some of the intangible and elusive aspects of the fieldwork learning experience. Thinking about practical activities projects and tasks first means that naming, conceptualising and articulating the basis of learning may come later. As such, students will inevitably begin to identify practice activities before deriving learning objectives and outcomes from them.

It is important to note, then, that there is a difference between practical activities and learning objectives: the activity is not in itself the learning. Therefore, a learning objective per se should not be conceptualised too heavily in the language of action or doing, as this runs the risk of conflating one with the other. The activity is the task or practice that will provide the opportunity for the realisation of the learning objective. The activity is more concrete (what will be done?); the objective is more abstract (what will be learnt?). In short, a learning objective should be conceptualised in the language of learning. For example:

58 Journal of Practice Teaching \& Learning 7(1) 2006-07, pp.50-66. ( 2007 Whiting \& Birch Ltd 
Planning for learning and learning about planning in social work fieldwork

Example 1

Conflating activities with objectives

\begin{tabular}{ll}
\hline Learning objective & Counselling clients \\
\hline Activity & Practice counselling with 6 clients \\
\hline
\end{tabular}

This is a very straight forward and simple example, but it is included to illustrate a common error in reasoning, known as a 'fallacy of equivocation' in which the meanings of the learning objective and activity are treated 'as though they were the same' (Munson, Conway $\&$ Black, 2004, p. 177). In this example, counselling clients is actually a strategy, and not a learning objective. Some important questions must be asked: What learning from counselling clients (a) is aimed for (b) has been achieved? By being more specific about the core of the learning, the practice/learning linkage could perhaps read like this:

Example 2

Specifying learning derived from an activity

\begin{tabular}{ll} 
Learning objective & $\begin{array}{l}\text { Understand and be able to apply solution- } \\
\text { focussed therapy (SFT) in counselling }\end{array}$ \\
\hline Activity & Practice principles of SFT in counselling \\
\hline
\end{tabular}

In negotiating agreements, some degree of preciseness will help in naming the distinctions between activities and learning. In this example, the distinction is such that the assessment of learning can be directed at the students understanding (knowledge) and learning of SFT and not at whether or not he or she 'counselled clients', which may be obvious, but not on its own evidence of learning. In the example above, it is inferred that because the student practices using the principles of SFT in counselling, they will therefore be able to understand and apply such principles. This kind of inference means to reach a 'conclusion about the unknown based on the known' (Cooper \& Patton, 2001, p. 25). In this example, what is known is that the student will practice using SFT in counselling, what is unknown, until evidence is sought, is whether or not they can understand and apply SFT in counselling, in other words, the learning. By being specific, higher degrees of reliability regarding evidence of the inferred nature of learning can be assessed.

It is important also to discriminate between an objective of practice

59 Journal of Practice Teaching \& Learning 7(1) 2006-07, pp.50-66. () 2007 Whiting \& Birch Ltd 
and an objective of learning. Again, these are potentially different and should be appropriately delineated. For example, a student may name an objective of practice but that does not indicate what is intended to be an outcome or objective of learning. For example:

Example 3

Conflating objectives of practice with objectives of learning

Learning Objective

To attend professional development training on risk and protective behaviours

Activity

Get approval and funding to attend 2-day training on risk and protective behaviours

In example three, attending professional development on risk and protective behaviours is certainly an objective, and getting approval and funding to go to the training may be a necessary activity at achieving this. However, like the previous example, attending training on its own is not a statement of learning. It is an objective all right, but it is not a learning objective. A critical question must again be asked: What learning will be derived from this activity? Framing the learning differently and in relation to the activity could then read as follows:

Example 4

Separating objectives of learning with objectives of practice

Learning Objective Learn and understand risk and protective behaviours that can be applied in child and adolescent development

Activity Attend professional development training on risk and protective behaviours

With this example, assessment can be directed not at whether the student attended the training, which may well be obvious, but what they learnt from the training and how they might incorporate this learning into their practice and thinking. This is important when it comes to assessing learning, as the student might correctly be able to demonstrate that they attended training, and thus met an objective, but may not be able indicate what was learnt from the training.

Similarly, the act of getting funding from the agency to pay for some training may be the strategy followed to realise some other

60 Journal of Practice Teaching \& Learning 7(1) 2006-07, pp.50-66. ( 2007 Whiting \& Birch Ltd 
Planning for learning and learning about planning in social work fieldwork

learning objective. In the following example, the student learns how to appropriately apply for and organise resources within an agency:

\section{Example 5}

Deriving a learning objective from a practice objective

\section{Learning Objective Learn how to appropriately obtain funding}

from an agency to attend training

Activity

Budget, plan and negotiate with

management to attend training

There is, of course, a fine line between the learning objective and the activity. At what point does the learning become the activity? At what point does the activity become the learning? In reality, they are connected in many ways and there is a crossing back and forth from doing and learning and thinking and reflecting. This complexity cannot be easily resolved within the confines of a rational planning model, and this is one of the main criticisms of rational decision-making (Ham \& Hill, 1993; Bridgman \& Davis, 2004). It is helpful to remember that in practice the learning/doing dynamic cannot always be assumed to be a neat causal relationship, with one automatically leading to the other; even if these relationships are indeed structured or predicted within learning plans of the kinds specified here. However, the point being made here is the importance of critically examining learning plans and trying to conceptually delineate between activities and the learning it is logically presumed they facilitate or activate, which can be named, articulated, reflected upon and, importantly, assessed.

The reason this becomes critical is because assessment in fieldwork is complex in that it depends on a number of variables that can be different from one context to the next. For example, differences and uniqueness of learning depend on what learning activities are available, the agency supervisor who determines how much support a student might get in undertaking certain tasks, the student's varying abilities to take up learning opportunities, and education staff views on what is important learning (Hughes \& Heycox, 2000). Assessment of learning on placement can be very subjective and personal (Eisenberg, Heycox \& Hughes, 1996), can be stressful (Gitterman \& Gitterman, 1979), can sometimes be on criteria that are not clearly articulated (Kimber, 1982), and can sometimes involve reluctance to pass critical or negative judgement. This means that students are rarely failed even if their competence in placement is questioned

61 Journal of Practice Teaching \& Learning 7(1) 2006-07, pp.50-66. (C) 2007 Whiting \& Birch Ltd 
(Eisenberg et al, 1996). Regardless, an important part of assessment involves the students' ability to name and articulate their own performance, conduct and learning. For a student to do this necessitates an ability to adequately conceptualise the many dimensions of their learning. This includes the concrete and visible aspects of their practice to the abstract and ethereal; the latter refers to learning that incorporates a change in the students understanding and representation of phenomena. A key part of assessment, therefore, is what the student and others can describe and articulate, and the describing and articulating of learning and competency should emanate from their learning plans.

While a plan might direct the conduct and practice of the student, and indicate signposts for attaining learning, the actual quality of the students conduct and learning needs to be linked to practice standards, which are not specifically embedded in the plan. For example, in Australia the AASW Practice Standards for Social Workers stipulate the expected competencies of social workers (AASW, 2003). These standards can be used to evaluate the quality of the students practice. That is, a learning plan guides and directs the conduct and learning of the student, while the practice standards provides the basis by which the quality of the students practice is assessed.

Given the role that learning plans play as tools to plan and document practice, an important aspect, then, is that they are often used as a convenient basis for providing a framework for evidencing learning. While there may be many components involved in assessing fieldwork (Hughes \& Heycox, 2000), they arguably rely on specific forms of evidence such as process recordings and minutes of meetings; others emphasise observation methods, such as direct observation and video taping, and participating in activities such as role plays and committee meetings (Cleak \& Wilson, 2004). In the case of learning plans, evidence is not to be confused simply with the methods of providing evidence, such as producing a document or writing a journal, but the actual observable, identifiable aspect of learning as an outcome - the public dimension of the students' practice and learning. Given that much of what is considered learning seemingly happens in intangible ways, what forms of evidence can demonstrate learning? If we come back to the main focus of the learning plan, which is about learning, then evidence and assessment should be directed at the conceptualisation of the specified objective inasmuch as it focuses on the practices and competencies of the student. In an assessment of this kind, Hopkins and 
Cooper (2000) state that it is necessary to gather sufficient evidence, in which they say evidence may be direct or indirect. Direct evidence refers to direct observation of the student's practice, and questioning of the student's understanding. Indirect evidence, which is less reliable, refers to 'student's self reporting, third-party reports from co-workers or other records from which competence can be inferred' (p.66). The latter is the more common form of evidence drawn upon (Hopkins \& Cooper, 2000), and this can be usefully summarise as follows:

1. What others observe of the student - supervisors, colleagues and clients are important sources of evidence of the student's competence and will often be called upon to testify to this.

2. What the student can articulate - being able to explain and articulate learning is an important and legitimate source of evidence.

In this sense, the main sources of evidence of learning are what the agency supervisor, and other stakeholders, can observe of the student's progress, performance and learning, and the way that the student can articulate and explain learning. For example, if the learning objective is 'understanding SFT' and the activity was 'counsel clients using SFT', the evidence of this is both the supervisor's reports of the student's practice using SFT, and the student's ability to name and articulate the main features of SFT as it has been developed and practiced in their placement. Here is an example of how this links together:

\section{Example 6}

Naming sources of evidence of learning

\begin{tabular}{ll}
\hline Learning Objective & $\begin{array}{l}\text { Understand solution-focussed therapy (SFT) } \\
\text { in counselling }\end{array}$ \\
\hline Activity & Practice SFT in counselling \\
\hline Evidence & $\begin{array}{l}\text { Supervisor/client/peer testimony of my } \\
\text { practice } \\
\text { I can name principles of SFT and the way I } \\
\text { applied them in practice }\end{array}$ \\
\hline
\end{tabular}

Finally, many learning plans denote estimates for timelines and there are a number of ways to approach this. For example, the student may wish to use timelines to indicate the end point of their learning objectives. That is, the student may indicate week ten of their field placement as 
the conclusion point to achieving a particular learning objective. This is a common way of doing it, but not advisable because learning is an ongoing process and placing a timeline on learning misses this point. It is both unrealistic and simplistic to expect conclusive knowledge of something that is probably complex, in a short time.

It is far better to specify timelines on the activities, as opposed to the learning objectives, since the former are more concrete and amenable to measurement by time. For example, the activity might be to 'practice SFT in counselling'. The student must now choose whether or not the timeline denotes the beginning or the end of the activity. Seeing as though field placement already has a built-in end point, it would be more appropriate to use time to denote a beginning point. That is, a timeline should indicate when the student thinks it necessary to start the activity in order to give themselves enough time to do it (and learn from it) before placement ends. For example, for the activity 'practice SFT in counselling' the student may estimate that they will need a good eight weeks to do that in order to achieve the learning objective - 'understanding SFT in counselling' - and so will designate week six as the time to commence counselling activity. If week eight has slipped by, and no counselling has begun, then the student may begin to revise the likelihood of achieving the objective of 'understand solution focussed therapy in counselling'. Linked together, the learning plan as it relates to this particular example could read as follows:

\section{Example 7}

Denoting a commencement of time linked to the activity

Broad objective concept Competent and professional use of counselling techniques

Practice activity $\quad$ Practice principles of SFT in counselling

Evidence of practice activity Conducted 16 counselling sessions using SFT

Learning objective or goal Understand and be able to apply SFT in counselling

\begin{tabular}{ll}
\hline Evidence of learning & $\begin{array}{l}\text { Supervisor's testimony of my practice } \\
\text { I can name principles of SFT and the way I } \\
\text { practiced it }\end{array}$ \\
\hline Timeline & Commence the activity by week 6 \\
\hline
\end{tabular}

64 Journal of Practice Teaching \& Learning 7(1) 2006-07, pp.50-66. ( 2007 Whiting \& Birch Ltd 
Planning for learning and learning about planning in social work fieldwork

\section{Conclusion}

This paper has raised some conceptual and logical problems that occur when trying to develop learning plans for fieldwork that are premised on a rational planning model. Such a model, which aims to link learning, practice, evidence, and time into a coherent plan, is, in our experience, a difficult task and risks becoming a meaningless and onerous burden for the beginning social work student. However, learning plans are necessary tools for providing a direction to fieldwork, and are often used as the basis for assessing learning. The aim of this paper has been to highlight some problems inherent in learning plans of the kind discussed, and stipulate some basic steps that students and educators can use to develop rigorous learning plans that facilitate the development and assessment of a student's fieldwork placement.

\section{References}

AASW (2000) Policy and procedures for establishing eligibility for membership of the AASW. Canberra: Australian Association of Social Workers. [Retrieved July 7, 2006, from http://www.aasw.asn.au/adobe/becomeamember/ membership_eligibility_2000.pdf]

AASW (2003) Practice standards for social workers: Achieving outcomes. Canberra: Australian Association of Social Workers. [Retrieved May 10, 2007 from http://www. aasw.asn.au/adobe/publications/Practice_Standards_Final_Oct_2003.pdf]

Bridgman, P. and Davis, G. (2004) The Australian Social Policy Handbook. (3rd ed.) Crows Nest, NSW: Allen \& Unwin

Briggs, L. and Kane, R. (2000) Ethics in fieldwork. in L. Cooper and L. Briggs (Eds.), Fieldwork in the Human Services. St Leonards, NSW: Allen \& Unwin (pp. 131-144)

Cleak, H., and Wilson, J. (2004) Making the Most of Field Placement. Southbank, Victoria: Thomson

Comeford, S.A. (2005) Engaging through learning, learning through engaging: An alternative approach to professional learning about human diversity. Social Work Education, 24, 1, 113-135

Cooper, L. and Briggs, L. (2000) Overview of teaching, learning and assessment in the field. In L. Cooper and L. Briggs (Eds.), Fieldwork in the Human Services. St Leonards, NSW: Allen and Unwin (pp. 3-9)

65 Journal of Practice Teaching \& Learning 7(1) 2006-07, pp.50-66. @ 2007 Whiting \& Birch Ltd 
Cooper, S. and Patton, R. (2001) Writing Logically, Thinking Critically. (3rd ed.) New York: Longman

ECU (2006) Social Work Fieldwork Manual. Bunbury, WA: Edith Cowan University, Faculty of Regional Professional Studies, Social Work Programme

Eisenberg, M., Heycox, K., and Hughes, L. (1996) Fear of the personal: Assessing students in practicum. Australian Social Work, 49, 4, 33-40

Garthwait, C.I. (2005) The Social Work Practicum: A guide and workbook for students (3rd ed.) Boston: Pearson Education

Gitterman, A., and Gitterman, N.P. (1979) Social work student evaluation: Format and method. Journal of Education for Social Work, 15, 3, 103-109

Ham, C. and Hill, M. (1993) The Policy Process in the Modern Capitalist State. New York: Harvester Wheatsheaf

Hopkins, J. and Cooper, L. (2000) The competency approach. in L. Cooper and L. Briggs (Eds.), Fieldwork in the Human Services. St Leonards, NSW: Allen \& Unwin (pp. 55-69)

Hughes, L. and Heycox, K. (2000) Assessment of performance. in L. Cooper and L. Briggs (Eds.), Fieldwork in the Human Services. St Leonards, NSW: Allen \& Unwin (pp. 84-95)

Jones, A. and May, J. (1992) Working in Human Service Organisations: A critical introduction. South Melbourne: Longman

Kahn, A.J. (1969) Theory and Practice of Social Planning. New York: Russell Sage Foundation

Kimber, S. (1982) Competence is incompetence: Evaluation of a social work student's practice. Contemporary Social Work Education, 5, 2, 93-104

Kiser, P. (2000) Getting the most from your Human Service Internship: Learning from experience. Belmont, CA: Brooks/Cole

Lishman, J. (2002) Personal and professional development. in R. Adams, L. Dominelli and M. Payne (Eds.), Social Work: Themes issues and critical debates. (2nd ed.) Basingstoke: Palgrave (pp. 95-108)

Munson, R., Conway, D., and Black, A. (2004) The Elements of Reasoning. (4th ed.) Belmont, CA: Wadsworth/Thomson Learning

O'Connor, I., Wilson, J., and Setterlund, D. (2003) Social Work and Welfare Practice. (4th ed,) Frenchs Forrest, NSW: Pearson Education Australia

Rogers, G. and Langevin, P. (2000) Negotiated learning contracts. in L. Cooper and L. Briggs (Eds.), Fieldwork in the Human Services. St Leonards, NSW: Allen \& Unwin (pp. 216-226)

Wall, T.F. (2001) Thinking Critically about Philosophical Problems: A modern introduction. Belmont, CA: Wadsworth/Thomson Learning.

66 Journal of Practice Teaching \& Learning 7(1) 2006-07, pp.50-66. ๑ 2007 Whiting \& Birch Ltd 